\title{
Sustainable supply chain management in the digitalisation era: The impact of
}

\section{Automated Guided Vehicles}

\author{
Dimitrios Bechtsis $^{\mathrm{a}, \mathrm{d},{ }^{*},}$, Naoum Tsolakis ${ }^{\mathrm{b}}$, Dimitrios Vlachos ${ }^{\mathrm{a}}$, Eleftherios Iakovou ${ }^{\mathrm{c}}$ \\ ${ }^{a}$ Laboratory of Statistics and Quantitative Analysis Methods, Department of Mechanical Engineering, Aristotle \\ University of Thessaloniki, P.O. Box 461, 54124 Thessaloniki, Greece \\ ${ }^{b}$ Centre for International Manufacturing, Institute for Manufacturing (IfM), Department of Engineering, \\ University of Cambridge, Cambridge CB3 OFS, United Kingdom \\ ${ }^{c}$ Department of Engineering Technology and Industrial Distribution, Texas A\&M University, College Station, TX \\ 77843-3367, United States \\ ${ }^{d}$ Department of Automation Engineering, Alexander Technological Educational Institute (ATEI) of Thessaloniki, \\ P.O. Box 141, 57400 Sindos, Thessaloniki, Greece
}

\begin{abstract}
Internationalization of markets and climate change introduce multifaceted challenges for modern supply chain (SC) management in the today's digitalisation era. On the other hand, Automated Guided Vehicle (AGV) systems have reached an age of maturity that allows for their utilization towards tackling dynamic market conditions and aligning SC management focus with sustainability considerations. However, extant research only myopically tackles the sustainability potential of AGVs, focusing more on addressing network optimization problems and less on developing integrated and systematic methodological approaches for promoting economic, environmental and social sustainability. To that end, the present study provides a critical taxonomy of key decisions for facilitating the adoption of AGV systems into SC design and
\end{abstract}

\footnotetext{
* Corresponding author. Tel: +30 2310 995896; fax: +30 2310996018.

E-mail address: dimbec@autom.teithe.gr (D. Bechtsis).
} 
planning, as these are mapped on the relevant strategic, tactical and operational levels of the natural hierarchy. We then propose the Sustainable Supply Chain Cube (S2C2), a conceptual tool that integrates sustainable SC management with the proposed hierarchical decision-making framework for AGVs'. Market opportunities and the potential of integrating AGVs into a SC context with the use of the S2C2 tool are further discussed.

Keywords: automated guided vehicles, sustainable supply chain management, literature taxonomy, decision-making framework, sustainable supply chain cube (S2C2) tool

\section{Introduction}

Internationalization of markets along with sustainability concerns stemming from regulatory schemes, business stakeholders and consumers’ environmental awareness underpin the adoption and exploitation of flexible and automated systems across supply chain (SC) operations (European Commission, 2015; Ventura et al., 2015; Verdouw et al., 2016). To that end, Automated Guided Vehicles (AGVs) are being integrated into existing manufacturing systems as they provide a range of benefits across economic, environmental and social sustainability dimensions (Craig and Dale, 2008; Kannegiesser et al., 2015; Wu et al., 2016), including (i) increased productivity (Negahban and Smith, 2014), labor cost savings (Gosavi and Grasman, 2009), (ii) reduced energy consumption (Acciaro and Wilmsmeier, 2015) and emissions (Geerlings and Van Duin, 2011), and (iii) enhanced safety (Duffy et al., 2003). 
Firstly, AGVs are generally related to significant fixed capital investment costs (Peterson and Michalek, 2013); nevertheless, AGVs provide a greater economic potential due to their lower maintenance expenditure compared to conventional vehicles and their capability to function on a 24/7 basis with minimum labor cost and human intervention. Additional cost savings derive from the associated improved safety and the resultant reduction in accidents, both for vehicle drivers and for pedestrian workers, as for instance forklift accidents occur in a frequency of one per three days (Bostelman, 2009). Labor cost savings except for the reduction of overtime labor payments is also promoting cost savings (Gosavi and Grasman, 2009; Kumar and Rahman, 2014). Furthermore, efficient and effective use of AGVs increases productivity in logistics operations and extends the service level of the entire SC. Particularly, AGVs are reported to decrease the delivery time of passengers' baggage to airport drop-off areas to 20-30 sec (Kalakou et al., 2015) and improve the service time of cranes in container terminals by almost 23\% (Gelareh et al., 2013). Secondly, the environmental sustainability ramifications of AGVs in SC operations are more evident and basically relate to the reduced energy consumption, specifically for the case of electric-powered AGVs (Lyon et al., 2012; Peterson and Michalek, 2013). AGVs generate reduced atmospheric emissions of Particle Matters and Greenhouse Gasses like $\mathrm{CO}_{2}$ and $\mathrm{NO}_{2}$ (Schmidt et al., 2015), while further minimizing emptytravel distances (Choe et al., 2016). Thirdly, the distinct contribution of AGVs refers to the social impact and the improvement of human safety (Bostelman et al., 2014; Duffy et al., 2003). The use of manual forklifts in logistics is considered among the most frequent causes of accidents. Notably, Sabattini et al. (2013) discuss that during the period 1998-2007 more than 3 million work accidents in the European Union (EU) were related mostly to transport and warehouse activities. The main reasons 
include errors caused by forklift drivers and blind spots present in manufacturing environments. To that end, the creation of ergonomic workplaces where people can cooperate and interact with machinery, the creation of skilled jobs, and the use of AGVs in hazardous environments are also considered in this context (Gómez et al., 2015; Shukla and Karki, 2016).

In this vein, the estimated number of global AGV system installations for logistics was 2,564 in 2014, recording an increase by $29 \%$ compared to 2013, while projections for the period 2015-2018 point to 13,300 AGV systems (International Federation of Robotics, World Robotics 2015). Primarily, AGVs provide automated loading, transportation, and unloading capabilities; hence main sectors of application include container terminals, manufacturing plants, warehouses, material handling systems and service industries (Fazlollahtabar et al., 2015). Indicatively, in 2012 the Amazon, the largest Internet-based retailer in the United States, acquired the warehouse robot maker Kiva Systems and deployed 15,000 AGVs across 10 of its proprietary warehouses with the aim to reduce delivery lead times and increase customer service levels (D' Andrea, 2012). Furthermore, the 2016 Material Handling Industry (MHI) report documents the prevalent utilization of AGVs in SCs with 51\% of the 900 surveyed professionals reporting the catalytic role of robotics and automation on disruptively shaping competitive advantages for the SCs (MHI, 2016). Moreover, $33 \%$ of the survey participants expressed their vivid interest in pursuing tactical investments on AGV systems over the forthcoming 24 months' period. Moreover, the “Pan-Robots” project (http://www.pan-robots.eu) funded under the EU 7th Framework Program is a prominent paradigm demonstrating the public interest on supporting research and development initiatives and promoting advancements on the 
field (Sabattini et al., 2013). In brief, the project aims at developing highly automated logistics systems to support future smart industries in terms of manufacturing flexibility, cost, energy efficiency, and accident-free operations.

Overall, the proven capability of AGVs to secure sustainable performance in a SC context at strategic, tactical and operational levels motivates novel research in the field (Giret et al., 2015). However, the sustainability ramifications of AGVs in a SC management context receive disparate attention and are only myopically tackled, while grounded theories that ratify and support the elaboration of AGV systems in a cradle-to-grave network perspective do not yet exist. To this effect, this study maps the existing research issues on a comprehensive framework for the incorporation of AGVs in SC management following the natural hierarchy of the decision-making process. In particular, the aim of this study is to address a number of critical issues for all involved stakeholders, such as potential investors, involved regulators and decision-makers, by attempting to answer the following research questions (RQs):

a) RQ1: What is the role of AGVs in digitalized manufacturing and smart distribution systems?

b) RQ2: Which decisions should be made on the strategic, tactical and operational levels for incorporating AGVs into SC network operations?

c) RQ3: Which regions of the SC ecosystem provide market opportunities for incorporating AGVs into the SC?

\section{Research methodology}

According to Rich (1992), a taxonomy is a specific classification scheme that allows for the systemic integration of the general similarities between scientific publications 
for a specific topic in a hierarchical fashion. In practice, taxonomy aims at classifying studies with interconnected findings in a structured way to explore any existing natural relationships and further comprehend the evolutionary connection between them (Tranfield et al., 2003). Indicatively, Hedden (2010) comments that " $a$ hierarchical taxonomy is a kind of controlled vocabulary in which each term is connected to a designated broader term (unless it is the top-level term) and one or more narrower terms (unless it is a bottom level term), and all the terms are organized into a single large hierarchical structure”.

As previously stated, the objective of this manuscript is to integrate AGVs into sustainable SC management through synthesizing knowledge from peer-reviewed literature. To that end, not merely a single AGV categorization framework is provided, but rather the focus is on an in-depth research for unveiling sustainability related decision variables and identify interconnections among sustainability issues and the SC management ecosystem. To ensure a high scientific output, the methodological approach includes two (2) phases: (i) literature identification, and (ii) decision-making framework development. An introductory section for defining the AGVs' characteristics precedes the methodological analysis for providing better insights to the identification of the AGVs' scope.

\subsection{AGVs technical description}

AGVs are used to a diversified field of applications that is expanding over time. The business sectors of interest include container terminals, flexible manufacturing systems, warehouses, agriculture, military operations, health management, mines and many more (Vis, 2006). 
The numerous types of AGVs and the multiple embedded systems can explain the variety of the fields of applications (Ullrich, 2015). Vehicle types include forklifts, unit loads, tows, clamps, hybrid vehicles and custom-made vehicles with specialization to the field of application. The AGV part categories that can be identified at hardware level include (i) the vehicle's mechanical parts (frame, steering controls, motors and transmission systems, special purpose robotic parts), (ii) the electronic parts and the electrical parts (central processing unit, microcontroller, sensors and electrical system) and (iii) the power source (electric, diesel, liquefied petroleum gas, biofuels and hybrid methods). The software architecture implements the vehicle's business logic namely the planning, routing, scheduling and dispatching techniques and the navigation systemwhich is closely connected to the steering controls. Steering controls include differential driving with two independently moving wheels, use of a steered wheel control and combined techniques. The navigation systems can be divided into two main categories: (i) path following techniques (wire, tape, laser markers), and (ii) free ranging AGVs (laser guidance with triangulation, inertial, natural features, vision, geoguidance GPS, in-house GPS and combinations of the above). The software management system can be central, hierarchical or fully decentralized in order to provide the maximum notion of flexibility.

AGVs' can vary from vehicles with manual controls for human drivers and supportive autonomous systems to fully autonomous unmanned vehicles. In the conducted research all the AGV categories were included and no exclusion was made as the focus was on the identification of the sustainability ramifications of AGVs. 


\subsection{Literature identification}

The developed framework is a synthesis of articles retrieved from four (4) databases, namely: (i) Scopus, (ii) Science Direct, (iii) Association for Computing Machinery Digital Library, and (iv) Emerald Insight. The referred databases offer a broad range of highly accredited management and engineering scientific journals with special focus on sustainability issues (Ahi and Searcy, 2013).

The appropriate literature identification phase took place from June 2015 to February 2016 with the reviewing process being really intensive by means of the quantity of the returned results. Additionally, the analysis was restricted to journal papers written in English language, while all papers were counterchecked to increase consistency.

At a first level, Boolean searches were conducted using as main search keywords the terms “Automated Guided Vehicle”, “Intelligent Autonomous Vehicle” (IAV), "Autonomous Vehicle" and the corresponding acronyms, either separately or in combinations (Milch and Laumann, 2016). The latter keywords were inserted in the “Title”, "Keywords” and “Abstract” search fields of the online databases’ interface.

Furthermore, additional search keywords were used in order to bound the research area and focus on research efforts that clearly associate with the sustainability ramification of AGVs. The refined search keywords elaborated at this stage include: “Automated Guided Vehicles”, “Autonomous Vehicles”, “Sustainable”, “Supply Chain”, “Environment”, “Economic”, “Social”, “Governmental”, “Effective”, “Efficient”, “Cost”, “Accident”, “Hazard” further including derivatives. The research did not consider the Transportation and conventional Automotive Industry thus 
excluding the keywords "Passenger cars”, “Freight transportation”, “Electric cars”. Finally, existing literature was further supplemented by cross-referenced publications provided by individual journals and publishers for supplementing the literature taxonomy. Notably, the authors found that the sustainability concept is mainly studied from 2009 onward. Especially, references about sustainability issues at the level of manufacturing operations, scheduling and control are limited prior to 2011 (Fang et al., 2011). What is more, AGVs have been only recently adopted in large-scale commercial applications thus highlighting new research avenues in the SC management field (D'Andrea, 2012). In this context, the study covered all relevant publications from 2009 to 2016.

Conclusively, following a high level of abstraction the reviewed AGV literature was clustered into three high level categories, i.e. "Field of Application”, “System Design Issues" and "System Architecture" (see Table 1), in order to identify and better understand the structure of the research field and use it as a guide to the decisionmaking framework.

[Table 1 about here]

\subsection{Decision-making framework development}

The provided decision-making framework was developed through a three (3) tier abstraction process (see Figure 1). Tier \#1 includes three key methodology processes: (i) identification of the $\mathrm{AGV}$ schemes to impose research at specific areas, (ii) identification of the decision variables used in the taxonomy's publication list, and 
(iii) examination of the cross-references of the selected papers to expand the search scope in the elaborated databases.

In addition, Tier \#2 aims at the creation of the AGV literature categorization scheme, the creation of the decision variables list, and the extension of the list with the use of cross-references from the selected papers. Briefly, Tier \#2 refers to the structural organization of the literature search results and to the actual clustering of the identified decisions.

Finally, Tier \#3 represents the most demanding part of the actual work performed including the selection of the databases, the searching with specific keywords and phrases, and the development of the publication lists under review. First level screening includes a thorough reading of the title, the abstract and the keywords. In case the publication under review meets the research objectives, the methodology proceeds with the study of the publication as a whole and on the occasion this stage is successful, the publication enters into the taxonomy. If, at any time, the publication does not meet the required objectives the next publication is selected from the list. This process was actually repeated for the all the aforementioned databases.

The present study aims at highlighting the contribution of AGV systems to sustainable SC management. Hence, a large number of publications was excluded from the analysis in case the decision variables were not clearly connected to the sustainability context. Although, many AGVs' optimization-oriented studies refer to the economic viability of the system, the economic ramification was considered to be out of the research scope, except for the case it was the main purpose of the publication. 
Figure 1. Research methodology flowchart.

\subsection{AGVs in the literature}

By February 15, 2016, a total of 39 articles were identified and included in the taxonomy. The annual allocation of the publications presents a continuously increasing trend for the sustainable context of the AGV systems. Especially, in 2016 the results are encouraging as the already available works account for the $70 \%$ of the total publications in 2015. Figure 2 also presents a pessimistic projection for 2016. To the authors' perspective, the depicted trend will become mainstream.

Figure 2. Distribution of publications by year.

Likewise, the distribution of the papers by journal is illustrated in Figure 3. Notably, collected journals cover a wide variety of scientific areas highlighting the disperse nature of the use of AGVs. Nevertheless, the distribution is quite uneven given that the "Journal of Cleaner Production" accounts for the vast majority of the articles included in the taxonomy, indicating the dominant role of the journal in the rapidly advancing field of sustainability.

Figure 3. Distribution of publications by journal.

As a next step, all collected articles were systematically clustered according to the specific sector or industry, as depicted in Figure 4. The majority of research efforts (36\%) refers to container terminals, while the expanded manufacturing industry 
gathers the $31 \%$ of the reviewed publications. Further, the agriculture, energy, health, material handling, and transportation and mining sectors embrace an equal $5 \%$ of the case works under study. Few studies focus on the application of AGVs on mass consumption markets, high technology products and the automotive industry.

Figure 4. Distribution of publications by sector or industry.

\section{Hierarchy of decision-making process}

The design, planning and management of sustainably efficient SCs that embrace AGV systems entails complex decision-making processes that extend across the strategic, tactical and operational levels. AGVs combine the often conflicting elements of cost, flexibility and adaptability; hence they could minimize the internal vulnerability of a SC and increase agility in individual organizations, particularly in a network economy context.

In Table 2 the inclusive hierarchical decision-making framework is provided for the design, planning and management of sustainable SCs through adopting and exploiting AGV technologies in order to overcome the repercussions of classical supply networks' operations in the modern digitalisation era. The provided framework is by no means a rigid model including an exhaustive list of all relevant decisions, but rather acts as a collection of decisions that the authors have identified as part of their on-going research.

With reference to the hierarchical levels, strategic decisions concern all SC stakeholders who are interested in developing policies or investing in AGVs that 
achieve crucial goals concerning sustainability in a long-term horizon. At the tactical level, SC management is related to medium-term decisions that convert strategies into actions short-term decisions at the operational level implement actions in several SC echelons.

[Table 2 about here]

Following the triple-helix sustainability model, in the following three subsections the authors discuss all the decisions involved in the strategic, tactical and operational levels of the natural hierarchy along with a taxonomy of related research efforts.

\subsection{Economic sustainability}

Decisions at the economic sustainability dimension concern all stakeholders that are interested in investing/developing AGV systems that would support SC network functionality and foster sustainability operations of economic sustainability ramifications prevail in the developed SC decision-making framework. Table 3 exhibits the matching of the critical decisions with the relevant research efforts properly taxonomized. In the subsections that follow, these decisions are further discussed.

[Table 3 about here]

\subsubsection{Decision-making at the strategic echelon}

Strategic level decisions include feasibility analysis, justification of investment and overall costs, and identification and utilization of relevant Key Performance 
Indicators (KPIs). Kavakeb et al. (2015) provide a study of IAVs in port container terminals and comment the capabilities of better maneuverability and increased containers' pick up/drop loading performance. Handling and logistics cost in container terminals accounts for up to $50 \%$ of the total terminal operation cost. The authors' simulation results reveal that IAVs are always as efficient as normal AGVs, but their intelligent features increase precision in material handling and significantly improve terminal performance. In addition, Kumar and Rahman (2014) demonstrate the sustainability impact of RFID-enabled process reengineering for the case of linens department at the Parkway Group hospitals in Singapore. The study results indicate that RFID technology and AGVs in clean linens processing reduce overall costs by $\$ 140$ per day (including reduced staff cost and a loss of 12 linens per quarter), while AGVs further reduce idle time in few processes by 50\%. Particularly, the authors develop a cost model that includes analytical cost parameters of all vehicles (AGVs, IAVs), capital expenditure, operational cost (i.e. wages, energy cost, etc.). Both the aforementioned works document the utilization of simulation modeling for conducting feasibility analyses and assessing the economic sustainability of AGV applications in the systems under study. Kavakeb et al. (2015) use the Flexsim Container Terminal simulation tool for conducting discrete event simulations, while Kumar and Rahman (2014) elaborate the ARENA software as a simulation tool.

Simulation techniques are also crucial for the determination of the workspace layout design (Ganesharajah et al., 1998; Leriche et al., 2015). The established facility layout often creates bottlenecks on the AGVs' movements; hence, proper decision-making assist in identifying potential bottlenecks and promotes specific modifications that provide added value to the installation. Indicatively, Leriche et al. (2015) illustrate the 
use of a new logistics system in the port of port Le Havre in France. The logistics system consists of an intermediate multimodal terminal serving as a hub for consolidating traffic with the hinterland. Simulation objectives include economic validation of the new logistics system, improvement of organizational aspects, sizing of resources needed and pedagogically communication of the new logistics system to various stakeholders. The new layout provides savings through the consolidation of containers and services along with the use of trains and electric trucks.

Following the facility layout design, special focus must be addressed to the determination of vehicle type and fleet size. For example, Gosavi and Grasman (2009) determine the optimal capacity of a single AGV manufacturing system with a closed loop simulation model of the system by using a C programming language based discrete event approach. The authors argue that AGVs increase systems' throughput and reduce inventory. The decision variables include the inventories at machine level and the capacity of the single AGV. Results show labor cost savings and that the increase in AGV's capacity beyond a certain point does not result in any further reductions in the total system inventory. Parreira and Meech (2011) who prove an anticipated reduction in labor costs of about $5-50 \%$ due to the utilization of a driverless system also support minimization of labor costs. Especially, the authors compare the performance outputs of an autonomous versus a manual haulage system. The elaborated KPIs concern system productivity, costs (labor, maintenance and fuel consumption), tire wear and truck useful life.

The utilization of information and data sharing for AGVs' communication, cooperation and coordination for realizing the fourth stage of industrialization 
(Industrie 4.0) is attracting the increasing academic and research interest. To this effect, Wang et al. (2016) focus on the vertical integration in industries and provide a framework for constructing the architecture of a smart factory. In addition, the authors describe the operational mechanism of the proposed architecture including: (i) smart shop floor artifacts, and (ii) big data analytics. The framework is further demonstrated for the case of the prototype smart factory production system called "German Research Centre for Artificial Intelligence" in Kaiserslautern, Germany, that elaborates a flexible conveying system with interoperating AGVs. Finally, the authors discuss technical challenges and benefits related to a smart factory, while they further suggest that Industrie 4.0 can assist in establishing sustainable production modes to tackle the global manufacturing challenges. Furthermore, Essers and Vaneker (2014) propose a hierarchical data-centric, distributed and decentralized manufacturing control system for promoting interoperability and cooperation between robotic systems and humans interacting in the same environment. The authors use different types of interfaces to develop appropriate data distribution service systems according to the safety level and the reliability needed; hence facilitating effective communication between heterogeneous machines, and dynamic reconfiguration and mass customization of production. Thereafter, smaller and personalized batch size productions can promote the reduction of investment costs by switching from large equipment to flexible robotic technologies.

Finally, Matsuda et al. (2012) propose a multi-agent oriented digital factory to support different production planning scenarios in virtual manufacturing systems. The proposed Information Technology (IT) tool is further implemented for the case of an autonomous assembly line of two mobile phones. The authors demonstrate that the 
provided IT platform supports the economic sustainability assessment of alternative industrial production settings from both factory and product perspectives.

\subsubsection{Decision-making at the tactical echelon}

At the tactical level, Negahban and Smith (2014) provide a detailed review of simulation methods applied in manufacturing systems and identify cost generation functions. Especially, the authors' classification includes three main cost sources, i.e. manufacturing system design, manufacturing system operation and simulation languages. The authors conclude that simulation in manufacturing system design and operation is expected to be continuously evolving to foster competiveness in the manufacturing sector, as it is an important part of the global economy. Except for the industrial manufacturing sector, resent trends in precision agriculture focus on the elaboration of highly automated and cooperating vehicles to improve farming efficiency and productivity. To that end, Reina et al. (2015) examine the growth of robotic technologies in agriculture and focus on semi or fully autonomous intelligent vehicles. The authors discuss that multi-sensory perception systems increase the ambient awareness of agricultural vehicles operating in crops. Particularly, stereovision, light detection and ranging, radar, and thermography sensors are evaluated on the farm field while different combinations are also considered. Experimental results indicate the effectiveness of these innovative methods in reliably detecting ground obstacles and therefore prevent potential accidents.

Furthermore, Franke and Lütteke (2012) developed a small-scale low cost AGV prototype to realize flexible and cost efficient one-piece-flow for industrial applications. The low cost vehicle prototype occupies a camera for surveying the 
facility layout of the plant and distinguishes vehicles, destinations and obstacles in order to plan the AGVs' paths. The central system is thus able to recognize the vehicles’ trajectories and apply shorter manufacturing cycle times whilst increasing accuracy and quality. They argue that AGVs can be equipped with onboard sensors in order to be more autonomous. In addition, Shukla and Karki (2016) argue that the main motive fueling the adoption of automated robotic technologies is the increase in productivity in tandem with efficiency improvements in cost and in the triplet Health, Safety and Environment (HSE). Typically, remotely operated ground and underwater automated vehicles function in challenging and hazardous environments by using sensors to gather real time data during operations. Hence, the authors identify the determination of sensor types that lead to the reduction of related cost, as a crucial decision-making parameter.

\subsubsection{Decision-making at the operational echelon}

The operational level decisions mainly concern the AGVs' operating space. Operational decisions include the determination of dispatching policies and the implementation of control techniques (positioning, localization, navigation and routing) along with the determination of advanced scheduling. Determination of efficiency criteria from an economic sustainability aspect is also a common referenced decision variable in the literature. Indicatively, Leite et al. (2015) identify the increase in efficiency using simulation and real data for the toothpaste industry. In addition, Reina et al. (2015) present recent trends in agriculture that regard cooperation amongst vehicles that improve efficiency whereas Shukla and Karki (2016) state the increase in productivity with the simultaneous cost efficiency improvement with the use of remotely operated vehicles (ground and underwater 
vehicles). Moreover, Luo and $\mathrm{Wu}$ (2015) discuss the cost ramifications related to operations effectiveness in automated container terminals through contemporarily tackling the issues of vehicle scheduling and container storage. Specifically, the authors provide an integrated mixed-integer programming model for the minimization of ships' berth time through determining dispatching rules of AGVs and yard cranes' allocation, while simultaneously taking into account both loading and unloading operations. The study results indicate that for small size (i.e. 5-25 containers) yards the proposed modeling approaches can provide near optimal solutions, a case that is not valid for large size instances (i.e. 25-200 containers), hence necessitating the application of heuristic methods. Carlo et al. (2014) review the current trends, developments and literature on transport operations in container terminals, which are critical in supply chains and they propose a classification scheme for transport operations in container terminals.

Notably, Luo and Wu (2015) suggest that for the case of large container terminals the ships' berth time increases significantly with the number of quay cranes due to traffic congestions and conflicts. Additionally, Choe et al. (2016) propose an online preference-learning algorithm that allows for the dynamic adaptation of AGVs' dispatching rules with response to real-time changing situations. The authors validated their algorithm through investigating two sets of experiments with various discharging and loading scenarios concluding that in most of the cases the learning time is less than $1 \mathrm{sec}$, which is sufficiently short for real-time processing in the context of AGV dispatching. Furthermore, the effectiveness of the proposed algorithm is tested compared to other methods available in literature. Ventura and Rieksts (2009) propose a dynamic programming algorithm for tackling the idle AGVs' 
positioning issues in unidirectional single loop systems and minimizing transportation costs. The authors provide a polynomial time algorithm for: (i) minimizing the maximum response time of multiple vehicles subject to restrictions on time available for AGVs to complete all of the delivery requests during a shift, and (ii) determining the optimal set of AGVs' dwell points at certain pick-up and drop-off station locations. Finally, the authors illustrate the applicability of the proposed algorithm through an indicative numerical experimentation concluding that the average utilization percentage of an AGV is inversely proportional to the number of AGVs.

Dang and Nguyen (2016) discuss the scheduling problem of mobile robots and machines in flexible manufacturing systems, especially in case the automated devices have to interrupt preemptive tasks in order to perform multiple non-preemptive transportation actions. To that end, the authors develop a generic heuristic algorithm to minimize the time required by the production and transportation tasks, while contemporarily satisfying a number of precedence constraints. The applicability of the proposed dynamic programming algorithm is demonstrated through a numerical experimentation.

Finally, Ganesharajaha et al. (1998) enumerate the advantages that AGV systems can offer including increased flexibility, better space utilization, reduction in overall operating cost, and easier interface with other automated systems. Their survey paper focuses both on design and operational issues that arise in AGV systems and concern Operational Research and Management Science researchers. Flow path design issues include fixed Pickup and drop off (P/D) points, variable P/D points, single loops, unidirectional and bidirectional, segmented flow paths and virtual flow paths for free 
ranging paths. The fleet sizing is determined by deterministic and stochastic analytical methods, simulation methods and by analyzing different environments. Operational issues vary significantly according to the facility layout and involve single line, single loop and complex networks.

\subsection{Environmental sustainability}

Growing world population, continuing industrialization and climate change trigger consumers' environmental sensitivity and purchasing decisions (Tsolakis et al., 2014), thus affecting the profitability of SCs. The plethora of studies in the field confirms the several environmental benefits emerging from the utilization of AGVs, especially for the case of logistics operations and distribution. In Table 4 the nature of the hierarchy of decision-making process is presented with refer to environmental sustainability, while providing the taxonomy of papers relevant to the design and planning of modern SCs embracing AGV systems.

[Table 4 about here]

\subsubsection{Decision-making at the strategic echelon}

At the strategic level, Dawal et al. (2015) explore the relation between Advanced Manufacturing Technology (AMT) practices (including AGVs) and environmental sustainability initiatives with the competitive manufacturing capabilities for the Malaysian automotive industry. They found that there are positive effects of sustainable environmental initiatives on the manufacturing capabilities of SMEs. The authors elaborated a cross-sectional survey and gathered data from 83 SMEs, while 16 industrial visits were also scheduled. The findings of the pair wise correlation analysis 
indicate that the majority of Malaysian automotive SMES have implemented AMT practices (50\%) and have adopted sustainability practices (80\%) resulting in the development of the following manufacturing capabilities: production flexibility, product quality, innovation, and cost reductions.

Furthermore, Matsuda and Kimura (2013) apply the digital eco-factory approach for assessing diverse production scenarios and thus ensure the increased productivity and sustainability performance of actual manufacturing systems through energy management and control policies. The whole structure of a digital eco-factory (machines, AGVs, products etc.) is simulated in order to assist the production system designers, machining tool manufacturers and vendors, and the manufacturing industry to make decisions into a sustainability context. Moreover, Shukla and Karki (2016) prepared a technical review of robotic systems used in offshore oil and gas industries outlining major the current HSE challenges and types of accidents in the sector, thus fueling a serious debate to governments, academia, environmentalists and industries. To that end, the authors also propose the use of robotic vehicles as a means to concurrently increase productivity, improve cost efficiency and effectively tackle HSE concerns in the offshore facilities of the oil and gas industries.

Additionally, the management of energy consumption is the focal topic of Acciaro et al. (2014) as they discuss the trend among port authorities towards adopting energy management strategies for coordinating and rationalizing energy demand in port operations. Especially, the authors study the European port of Hamburg, Germany, and comment the port's pilot project regarding the use of certified green energy for the electrification of its AGVs for reducing GHG emissions, noise levels and costs. 
The study findings suggest that AGVs can offer energy efficiency gains that lead to the improved economic and environmental sustainability performance of ports, thus enhancing their global competitiveness. In the same vein, Acciaro and Wilmsmeier (2015) discuss the challenges related to energy efficiency along maritime logistics chains. The authors provide a short review on the existing literature and underline the need for shipping stakeholders and container port authorities to adopt modern technological solutions to promote energy efficiency and environmental sustainability in their operations.

Finally, Fuc et al. (2016) argue that most of the times economic aspects of the adoption of electric vehicles are taken into consideration while environmental consequences are overlooked. The authors worked with the ISO 14044 and the IMPACT 2002+ methods for life cycle impact assessment and their focus was on internal transport. The conditions used are close to those of the actual exploitation of forklifts to evaluate vehicles environmental pollution. Results show that using electric forklifts has a significantly smaller environmental impact compared to liquefied petroleum gas and diesel forklifts.

\subsubsection{Decision-making at the tactical echelon}

At the tactical level of the natural hierarchy, the selection of AGVs' charging and refueling methods is highlighted by Schmidt et al. (2015). The authors provide a seminal study that confirms the economic, environmental and technical advantages of battery powered AGVs (B-AGVs) compared to the diesel-powered counterparts, through examining the real case study of the Altenwerder Container Terminal in Germany. A major conclusion is that in the future B-AGVs can develop even more 
efficient as environmental legislation becomes more stringent. Furthermore, Geerlings and Van Duin (2011) analyze the development of a methodology for monitoring energy consumption and the resulting $\mathrm{CO} 2$ emissions for the container terminal in the port of Rotterdam in the Netherlands. The proposed model shows that by adopting specific terminal layouts it would be possible to reduce generated CO2 emissions by nearly 70\%. Similarly, Leriche et al. (2015) use agent based simulation in the Le Havre port in France to illustrate that by using electric powered vehicles annual savings of 500,000 tones of CO2 could be achieved. Moreover, at tactical level Schmidt et al. (2014) study the sustainability of controlled charging concepts applied to commercial fleets of AGVs operating in closed transport systems. The authors analyze data gathered at the port of Hamburg, Germany, where an electric vehicle fleet is utilized for loading and unloading containerships. The authors investigate three (3) alternative charging strategies: (i) optimizing energy procurement, (ii) trading load-shifting potential on control markets, and (iii) applying a combination of the previous two. The study findings indicate that the adoption of any charging strategy provides economic benefits with the prospective reductions in operational costs accounting for more than $65 \%$ compared to the case of utilizing diesel-powered vehicles.

In the same vein, Hopf and Müller (2015) study the energy and resource consumption efficiency in manufacturing sites in daily planning and operational activities. The authors apply a state-of-the-art energy information system in the context of a digital factory and use energy cards to provide energy consumption details about all the parts in a manufacturing system, hence fostering energy consumption visibility and 
optimization. In their use case scenario, they recognize electrical AGVs as low energy vehicles, which can minimize energy consumption.

\subsubsection{Decision-making at the operational echelon}

At the operational level, the determination of efficiency criteria, the determination of dispatching policies and the determination of scheduling policies based on environmental decisions are frequently referenced in the related literature. Indicatively, Xin et al. (2014) study the improvement of the environmental performance of container terminals under the consideration that energy consumption needs to be reduced to promote sustainability. The authors use a hierarchical controller to determine time windows that maximize the space for energy efficiency and introduce a benchmarking system for container handling in an automated container terminal. Following, Xin et al. (2015b) provide a methodology for determining the trajectory of interacting machines that transport containers between the quayside area and the stacking area in an automated container terminal.

Moreover, Lee et al. (2015) make a comparative evaluation in container terminals in order to promote reduction in energy consumption and improve operating efficiency. Port operators experience high pressures by consumers, governments and businesses to reduce their ecological footprints through reducing the total number of cycles in daily operations. To that end, Lee et al. (2015) use analytical models to examine single and dual cycle operational modes of quay cranes, AGVs and yard cranes and analyze both operating and energy efficiency parameters. The authors state that dual cycle strategies achieve $42.2 \%, 37.9 \%$ and $0.42 \%$ reductions in the number of 
required cycles for quay cranes, AGVs and yard cranes respectively, compared to single cycle mode.

\subsection{Social sustainability}

Social sustainability is related to the autonomous nature of AGV systems along with their capability to cooperate with humans and their functioning environment to promote reductions in the number of work accidents, to minimize human errors and to effectively explore feasible scheduling and routing solutions in real time. Remarkably, the aforementioned positive social impacts are further augmented in case one considers the capability of AGVs to operate on a 24/7 basis. Table 5 exhibits the matching of the social SC decisions, with the relevant research efforts properly taxonomized.

[Table 5 about here]

\subsubsection{Decision-making at the strategic echelon}

At the strategic level, Martín-Soberón et al. (2014) study the concept of automation solutions in port container terminals and provide a methodology facilitating the selection of existing technologies and processes' re-engineering for the effective design of terminal operations. This results in the standardization of performance and service levels, the elimination of uncertainty in response times and the reduction in operational costs and human errors. In addition, the authors discuss the advantages and disadvantages of planning a port container terminal automation system, while emphasizing on the resulting social sustainability ramifications. Leite et al. (2015) examined different simulation scenarios for the toothpaste industry in Brazil and they 
support that the use of AGVs increases efficiency and minimizes hazards and accidents by reducing human errors. The authors suggest simulation as an effective decision-making tool for improving manufacturing processes and guarantying quality and agility in production. In addition, Duffy et al. (2003) developed an internet based virtual simulation environment in order to improve facility design and reduce hazards. The use of specific KPIs -errors, injury compensation, lost work time, severity of error, cost of training, improved potential for insurance savings- assisted the authors in quantifying risk mitigation by understanding the health, safety and ergonomic requirements of the workspace. The authors claim that the fundamental elements of a virtual factory that may trigger realistic industrialists’ perceptions include employees, movement and communication among workers, sound, AGVs, and illumination.

Lee and Leonard (1990) tackle the significant issue of job creation and the widespread belief that AGVs could jeopardize job positions. The authors state that AGVs promote a gradual transformation in the nature of the human workplace through changing the working environment and the occupational structure. Indicatively, machine monitoring is crucial in AGV supervision thus providing impetus for the creation of skilled jobs and improved ergonomics for workers. At the end, everything depends on people as technology itself cannot guarantee the production outcomes; hence necessitating the utilization of information and data sharing for communication, cooperation and coordination between humans and machines. Furthermore, Krüger et al. (2009) study the intimate cooperation between workers and automated intelligent machines for improving the efficiency of complex processes. This cooperation can minimize the social and economic costs of work related injuries (i.e. lower back pain, spine injuries etc.) by applying ergonomic measures. AGVs are characterized as ready 
to make one-step forward with the advance of electronics and autonomous navigation systems.

Kabe et al. (2010) examine the introduction of standards and regulations to improve human and robot operator's safety. The authors recognize the significant benefits of service robots in the social culture and the inherent dangers that occur in the humanrobot interaction. Three basic guideline categories are recognized: (i) Category A that involves the types of communication protocols among robotic systems, (ii) Category B that refers to the AGVs used in industrial environments, and (iii) Category $\mathrm{C}$ that identifies the rescue type robots. The authors suggest the development of a system guideline or a regulatory scheme for service robots.

\subsubsection{Decision-making at the tactical echelon}

At the tactical level, Gázquez et al. (2016) study the use of autonomous and semiautonomous vehicles in farming environments and greenhouses in order to control pests and crop diseases. The safety improvements are enhanced with the use of sensors as agricultural environments can become harmful for human health under certain conditions. For example, toxic pesticides can be applied without the human presence, while they are efficiently and securely distributed to the farming area without the elaborating skilled labor. Moreover, Reina et al. (2015) examine the evolution of robotic sensors in agriculture and focus on semi or fully autonomous intelligent vehicles to improve efficiency and safety. The authors discuss that multisensory systems increase the ambient awareness of agricultural vehicles operating in crops thus allowing safe driving in crop fields. The study findings indicate the effectiveness of sensory systems in reliably detecting ground obstacles. 
Gómez et al. (2015) perform an analysis of optimized trajectories in terms of clearance, smoothness and execution time under hazardous maintenance operations like transportation of equipment for storage, refurbishment and repair. Particularly, the authors examine transport scenarios for AGVs for the planning of operations in the International Thermonuclear Experimental Reactor located at the Cadarache facilities in the south of France. Transport operations for the contaminated components require precise and accurate simulation tasks in order to identify hazards and propose safety improvements.

\subsubsection{Decision-making at the operational echelon}

Notably, mining is one of the few non-industrial sectors identified as energy intensive. Therefore, climate change concerns and governmental policies imposing carbon emissions taxes encouraged stakeholders in improving energy efficiency of mines with the loading and hauling operations presenting the highest potential for improvements. In this context, Awuah-Offei (2016) discuss that autonomous dump trucks increase energy efficiency by removing the human factor or by even assisting operators in making optimal decisions. The authors focus on the role of operators in achieving social efficiency performance for the loading and hauling operations in the mining sector.

Moreover, Reina et al. (2015), argue that resent trends in agriculture include cooperating vehicles that increase safety levels. Multi- sensory perception systems increase the ambient awareness of agricultural vehicles that operate in open crop fields. 


\section{Results and critical discussion}

The analysis has clearly demonstrated that the incorporation of AGV systems in SC management is a rapidly evolving research field due to the evident positive sustainability impacts. In the subsections that follow a summary and a critical discussion of the main findings of our on-going research is presented. Furthermore the sustainable supply chain cube (S2C2) acts as a conceptual tool that integrates sustainable SC management with the provided hierarchical decision-making framework for AGVs.

\subsection{Key findings}

Figure 5 illustrates the allocation of the research works to the sustainability dimensions, among which the economic ramifications of AGVs are mostly (49\%) investigated in a SC context. Furthermore, environmental and social components represent $30 \%$ and $21 \%$ respectively of the existing studies in the related body of literature. The results confirm that although AGVs can have direct economic (i.e. both temporal and monetary) implications that affect SC networks' configuration and responsiveness (Bilge et al., 2006; Roh et al., 2014), several environmental benefits emerge due to optimized vehicles' routing schedule, specifically for the case of electric powered AGVs (Schmidt et al., 2015). In addition, AGVs are associated with apparent social benefits (Bostelman, 2009; Sabattini et al., 2013) that are often obscure or irrelevant to operations in traditional supply networks.

Figure 5. Distribution of publications by sustainability dimension. 
Furthermore, Figure 6 depicts that the preponderance (45\%) of the reviewed publications, concerning the elaboration of AGVs towards sustainable SCs, refers to strategic issues. The corresponding research scope focuses on high-level aspects of the investigated value chains including capital expenditures (Schmidt et al., 2015), warehouse and port layout design etc. Following, the 35\% of the studies is classified to the operational level of the natural hierarchy, thus further confirming that for the specific case of AGVs the strategic decisions aim at tackling operational challenges and creating additional opportunities for SC effectiveness improvements (Kumar and Rahman, 2014). Decisions at the tactical level are limited (20\%) focusing on the assessment and application of intermediate interventions to effectively embed AGVs in common SC operations.

Figure 6. Distribution of publications by level of hierarchy.

Overall, the analysis demonstrates a lack of research efforts on AGVs' exploitation across the entire spectrum of SC operations, but rather automated systems are mainly used in the logistics operations focusing on warehouse management and distribution and on the manufacturing division. Especially, the research results confirm that although port authorities undoubtedly constitute the main stakeholder to have actually realized the exploitation of AGVs (Choe et al., 2016; Xin et al., 2015a,b), several other sectors that share common operational characteristics, like logistics/dispatching/scheduling/planning issues, are now recognizing the potential of automated systems in their SCs (Bocewicz et al., 2014). 
Furthermore, it is hard to identify in the literature any refering to commercial AGV products and to key decisions for adopting them to SCs is hard to identify in the literature. Moreover, simulation is used as the main tool for analyzing information utilization and data sharing. Finally, identification and utilization of appropriate KPIs for accounting and assessing the environmental impacts of interventions in SCs is embedded to the industries' digitalisation process.

\subsection{Sustainable supply chain cube}

Except for providing insightful statistics, the scope of the provided taxonomy is to document the gaps in the existing body of literature that could highlight opportunities for integrating AGVs into the sustainable SC management field. First, the rather limited yet rapidly increasing number of research contributions on AGVs is identified. In fact, it is evident that published works related to sustainability ramifications of AGVs across SC levels have increased significantly during the last five years, indicating the emerging significance of automations in shaping SCs within the forthcoming digitalisation era. However, the analysis of the studies in an integrated SC context is rather challenging as AGVs are only myopically considered at different SC levels of operations, thus preventing a comprehensive evaluation of sustainability. Furthermore, the majority of studies focus on the exanimation of scheduling algorithms and experimental investigation of conceptual AGV systems within a setting. Therefore, only a subset of publications refers to real case studies and provides a vision about the applicability of AGVs in SCs.

Up to this end, the sustainability triple-helix framework is used as a roadmap for developing the proposed AGV hierarchical decision-making framework. Conversely, 
it is a challenging issue to present a tool that documents the incorporation of AGVs' sustainability related decisions within the complex SC management framework. To this effect, the authors of the present study identify the key regions that offer research opportunities to academicians and practitioners in adopting AGV systems to a SC ecosystem, by considering the proposed hierarchical decision-making framework.

The SC ecosystem is often represented as a cube in the three-dimensional space (Shapiro, 2000). The SC cube originally included functional (purchasing, manufacturing, transportation and warehousing), spatial (vendors, facilities and markets) and inter-temporal (strategic, tactical, operational) planning dimensions. The functional dimension was further discussed at the SC matrix context (Meyr et al., 2002) and included procurement, production, distribution and sales levels in order to integrate the material flow across the SC. In addition, the building blocks of the SC cube were later proposed as the FAMASS (FORAC Architecture for Modeling Agentbased Simulation for Supply chain planning) methodological framework for analyzing requirements (Santa-Eulalia et al., 2012) and identifying the possible planning and control functions of a typical SC. Furthermore, as AGVs act as entities planned to perform part or the entire spectrum of SC processes with a degree of autonomy, execution has also to be considered as an inter-temporal planning dimension to allow for the future consideration of automated systems’ collaboration capabilities.

To that end, the sustainable SC cube is proposed as a useful tool for integrating and implementing AGV systems into a SC context. Thereafter, the proposed tool could be used for also highlighting market opportunities for AGV systems. Regarding the structure of the cube, the three axes represent: (i) the basic SC level of operations, i.e. 
procurement, manufacturing, distribution, sales, (ii) the involved SC stakeholders, i.e. vendors, facilities, clients, customers, and (iii) the level of the decision-making natural hierarchy, i.e. strategic, tactical, operational and execution. Each building block of the cube represents: (i) a well referenced region in the extant literature, (ii) a gap identified as a mature region for the incorporation of AGV systems, or (iii) a gap identified as a non-mature region. Figure 7 illustrates the sustainable SC cube proposed as part of our research. This study clearly identifies the great opportunities for applying AGVs at the sales/customer and client level, thus establishing novel interaction patterns between clients and customers. Finally, mature regions for the incorporation of AGVs can be found at strategic and tactical levels and involve all the SC stakeholders at all the operational levels.

Figure 7. Sustainable supply chain cube (S2C2).

\section{Conclusions}

In recent years, globalization has imposed major reconfiguration options for modern SCs to address sustainability requirements stemming from environmental changes, detailed regulatory schemes and increasing variability in demand quantity and quality profiles (Manzini et al., 2015). Experts and company leaders identify internal and external drivers that lead to corporate sustainability. Corporations are recognizing their pivotal role towards sustainability and should make efforts to apply organizational, holistic changes as this could embed sustainability into companies' systems (Lozano, 2012). In this context, the use of AGVs in digitalized manufacturing and smart distribution systems can promote sustainability (Wang et al., 2016). Especially, the use of environmental friendly and automated transfer and distribution 
equipment is among the most dominant trends in today's smart manufacturing environment due to low operational costs and great efficiency. From the authors' point of view, AGVs are at a maturity stage of development and can dominate in production, manufacturing and material handling schemes. The study reveals the heterogeneous nature of AGV systems along with their application in specific operations. AGVs can efficiently and effectively conduct daily manufacturing and SC related processes, functioning autonomously and in cooperation with other AGVs, and interacting with human working capital. AGVs' employability must be strongly referenced within the sustainability context as they can tackle economic, environmental and social sustainability challenges. To the best of our knowledge, this is the first review paper that directly connects sustainability issues to the deployment of AGVs within a SC management ecosystem.

Taking into consideration the SC perspective, this paper provides a critical literature taxonomy on AGVs' decision-making in multiple production sectors, including strategic, tactical and operational echelons of the natural hierarchy. Specifically, the findings of the taxonomy indicate the following insights. Existing efforts mainly refer to the economic ramifications of AGVs in SCs and occasionally to environmental aspects. Social sustainability aspects stemming from the adoption of AGVs in SC management are rarely discussed. The obtained insights highlight that AGVs shape a novel research field among practitioners, as an increasing number of companies is interested in adopting automated systems for enhancing corporate efficiency and sustainability performance. To that end, the proposed framework aims at supporting corporations to consider AGV systems in a systematic manner, through identifying and classifying a set of strategic, tactical and operational decisions for designing 
sustainable SCs. Finally, the paper presents the S2C2 tool for identifying gaps and overlaps of key issues tackled by the existing research efforts, thus revealing opportunities for additional research.

\subsection{Limitations}

The present work must take into account the limitations deriving from the selection process of research efforts included in the taxonomy. The authors excluded a large number of publications relevant to AGV systems in case the decision variables where not clearly connected to the sustainability context.Many AGVs' publications consider optimization algorithms thus making inferences to the economic sustainability dimension. To that end, it should be stated that the economic ramifications were conceived to be out of the research scope in case they were not the main research aim but rather just the outcome of an optimization algorithm.

Furthermore, all types and categories of $\mathrm{AGV}$ based vehicles are included at the current research as the main interest of the authors was the sustainability context. Different fields of applications require special purpose vehicles ranging from fully autonomous unmanned vehicles to manually driven semi-autonomous vehicles. Although the inclusion of all vehicles leads to a general-purpose decision making framework, it lacks specialization that may be critical for emerging fields of applications.

\subsection{Discussion beyond state-of-the-art}

AGVs have reached an age of maturity and can add value to the digitalisation of the SC from cradle-to-grave by promoting the use of a holistic approach to the existing 
body of knowledge. The authors envision the progress of information technology, industrial robots, service robots and logistic systems in a SC sustainability context with high visibility. Moreover, digital SCs and smart manufacturing are paving novel research avenues where the use of automation will be closer than ever to the final consumer needs. In this context, the authors will primarily focus their future research efforts on the areas that are less referenced in the literature, namely:

- at the economic sustainability dimension on the minimization of energy consumption, defective parts (crapped units or rejected units) and semistructured products,

- at the environmental sustainability dimension on the environmental accountability from the SC partners and the minimization of waste, and

- at the social sustainability level on the continuously changing labor scheme due to the AGV and robotics penetration and on the minimization of nuisance at the levels of noise, vibrations and harshness in general.

Notably, the governmental sustainability level and environmental regulations must also be included in future research (Schmidt et al., 2015) where researchers should focus on the creation of widely accepted standards (cross section of suppliers, clients, academia and government) and to assess taxation incentives for the adoption of AGVs in the markets enhancing commitment to sustainable manufacturing and corporate social responsibility.

Further research will also consider the use of fully autonomous, intelligent vehicle fleets acting as multiagent systems in container terminals (Kavakeb et al., 2015; Leriche et al., 2015), in manufacturing (Matsuda and Kimura, 2013; Negahban and 
Smith, 2014) and in agriculture (Gázquez et al. 2015; Reina et al., 2016). Environmental friendly AGVs acting as intelligent agents can assist manufacturers and practitioners in minimizing cost, increase flexibility and avoid single points of failure while working on a 24/7 basis in a labor intensive and accident free workplace. Fully autonomous unmanned vehicles, an emerging type of AGVs should be independently examined in order to understand their usage and capabilities, and smoothly incorporate them to the SC context for promoting sustainability.

\section{References}

Acciaro, M., Ghiara, H., Cusano, M.I., 2014. Energy management in seaports: A new role for port authorities. Energy Policy 71, 4-12. doi:10.1016/j.enpol.2014.04.013

Acciaro, M., Wilmsmeier, G., 2015. Energy efficiency in maritime logistics chains. Research in Transportation Business \& Management 17, 1-7. doi:10.1016/j.rtbm.2015.11.002

Ahi, P. and Searcy, C., 2013. A comparative literature analysis of definitions for green and sustainable supply chain management. Journal of Cleaner Production 52, 329-341. doi:10.1016/j.jclepro.2013.02.018

Asef-Vaziri, A., Laporte, G., 2009. Integration of operational policies into the design phase of a material handling network. International Journal of Advanced Operations Management 1 (1), 108-134. doi:10.1504/IJAOM.2009.026526

Awuah-Offei, K., 2016. Energy efficiency in mining: a review with emphasis on the role of operators in loading and hauling operations. Journal of Cleaner Production 117, 89-97. doi:10.1016/j.jclepro.2016.01.035 
Bilge, Ü., Esenduran, G., Varol, N., Ozturk, Z., Aydın, B., Alp, A., 2006. Multiattribute responsive dispatching strategies for automated guided vehicles. International Journal of Production Economics 100 (1), 65-75. doi:10.1016/j.ijpe.2004.10.004

Bocewicz, G., Nielsen, I., Banaszak, Z., 2014. Automated guided vehicles fleet match-up scheduling with production flow constraints. Engineering Applications of Artificial Intelligence 30, 49-62. doi: 10.1016/j.engappai.2014.02.003

Bostelman, R., Teizer, J., Ray, S.J., Agronin, M., Albanese, D., 2014. Methods for improving visibility measurement standards of powered industrial vehicles. Safety Science 62, 257-270. doi:10.1016/j.ssci.2013.08.020

Bostelman, R., White Paper, 2009. Towards Improved Forklift Safety. National Institute of Standards and Technology, PerMIS 2009, 320-325.

Carlo, H.J., Vis, I.F.A., Roodbergen, K.J., 2014. Transport operations in container terminals: Literature overview, trends, research directions and classification scheme. European Journal of Operational Research 236, 1-13. doi:10.1016/j.ejor.2013.11.023

Choe, R., Kim, J., Ryu, K.R., 2016. Online preference learning for adaptive dispatching of AGVs in an automated container terminal. Applied Software Computing Journal 38, 647-660. doi:10.1016/j.asoc.2015.09.027

Craig, R.C., Dale, S.R., 2008. A framework of sustainable supply chain management: moving toward new theory. International Journal of Physical Distribution \& Logistics Management 38 (5), 360-387. doi: 10.1108/09600030810882816

D'Andrea, R, 2012. Guest Editorial - A revolution in the warehouse: A retrospective on Kiva Systems and the grand challenges ahead. IEEE Transactions on 
Automation Science and Engineering 9 (4), 638-639. doi: 10.1109/TASE.2012.2214676

Dang, Q.V., Nguyen, L., 2016. A Heuristic Approach to Schedule Mobile Robots in Flexible Manufacturing Environments. Procedia CIRP 40, 390-395. doi:10.1016/j.procir.2016.01.073

Dawal, S.Z.M., Tahriri, F., Jen, Y.H., Case, K., Tho, N.H., Zuhdi, A., Mousavi, M., Amindoust, A., Sakundarini, N., 2015. Empirical evidence of AMT practices and sustainable environmental initiatives in malaysian automotive SMEs. International Journal of Precision and Manufacturing 16, 1195-1203. doi:10.1007/s12541-015-0154-6

Duffy, V.G., Wu, F.F., Ng, P.P.W., 2003. Development of an Internet virtual layout system for improving workplace safety. Computers in Industry 50, 207-230. doi:10.1016/S0166-3615(02)00121-5

Essers, M.S., Vaneker, T.H.J., 2014. Evaluating a Data Distribution Service System for Dynamic Manufacturing Environments: A Case Study. Procedia Technology 15, 622-631. doi:10.1016/j.protcy.2014.09.023

European Commission, 2015, Paris Agreement. http://ec.europa.eu/clima/policies/international/negotiations/paris/index_en.ht m (accessed 09.03.2016.).

Fang, K., Uhan, N., Zhao, F., Sutherland, J.W., 2011. A new approach to scheduling in manufacturing for power consumption and carbon footprint reduction. Journal of Manufacturing $\quad$ Systems 30, 234-240. doi:10.1016/j.jmsy.2011.08.004

Fazlollahtabar, H., Saidi-Mehrabad, M., Balakrishnan, J., 2015. Mathematical optimization for earliness/tardiness minimization in a multiple automated 
guided vehicle manufacturing system via integrated heuristic algorithms. Robotics and Autonomous Systems 72, 131-138. doi: 10.1016/j.robot.2015.05.002

Franke, J., Lütteke, F., 2012. Versatile autonomous transportation vehicle for highly flexible use in industrial applications. CIRP Annals - Manufacturing Technology 61, 407-410. doi:10.1016/j.cirp.2012.03.048

Fuc, P., Kurczewski, P., Lewandowska, A., Nowak, E., Selech, J., Ziolkowski, A., 2016. An environmental life cycle assessment of forklift operation: a well-towheel analysis. The International Journal of Life Cycle Assessment, 1-14. doi:10.1007/s11367-016-1104-y

Ganesharajah, T., Hall, N.G., Sriskandarajah, C., 1998. Design and operational issues in AGV-served manufacturing systems. Annals of Operations Research 76, 109-154. doi:10.1023/A:1018936219150

Gázquez, J.A., Castellano, N.N., Manzano-Agugliaro, F., 2016. Intelligent low cost telecontrol system for agricultural vehicles in harmful environments. Journal of Cleaner Production 113, 204-215. doi:10.1016/j.jclepro.2015.11.015

Geerlings, H., Van Duin, R., 2011. A new method for assessing CO2-emissions from container terminals: A promising approach applied in Rotterdam. Journal of Cleaner Production 19, 657-666. doi:10.1016/j.jclepro.2010.10.012

Gelareh, S., Marzouki, R., McGinley, M., Murray, R., 2013. Scheduling of intelligent and autonomous vehicles under pairing/unpairing collaboration strategy in container terminals. Transportation Research Part C: Emerging Technologies 33, 1-21. doi: 10.1016/j.trc.2013.04.006 
Giret, A., Trentesaux, D., Prabhu, V., 2015. Sustainability in manufacturing operations scheduling: A state of the art review. Journal of Manufacturing Systems 37, 126-140. doi:10.1016/j.jmsy.2015.08.002

Gómez, J.V., Vale, A., Garrido, S., Moreno, L., 2015. Performance analysis of fast marching-based motion planning for autonomous mobile robots in ITER scenarios. Robotics and Autonomous Systems 63, 36-49. doi:10.1016/j.robot.2014.09.016

Gosavi, A., Grasman, S.E., 2009. Simulation-based optimization for determining AGV capacity in a manufacturing system. Proceedings of the Institute of Industrial Engineers Research Conference, Miami, FL, pp. 574-578. doi:10.13140/2.1.1059.3928

Hedden, H., 2010. The accidental taxonomist, second ed. Medford, New Jersey: Information Today Inc.

Hopf, H., Müller, E., 2015. Providing energy data and information for sustainable manufacturing systems by Energy Cards. Robotics and Computer-Integrated Manufacturing 36, 76-83. doi:10.1016/j.rcim.2014.12.006

International Federation of Robotics, World Robotics 2015. Service Robot Report, http://www.ifr.org/service-robots/statistics/ (accessed 09.03.2016).

Kabe, T., Tanaka, K., Ikeda, H., Sugimoto, N., 2010. Consideration on safety for emerging technology - Case studies of seven service robots. Safety Science 48, 296-301. doi:10.1016/j.ssci.2009.11.008

Kalakou, S., Psaraki-Kalouptsidi, V. and Moura, F., 2015. Future airport terminals: New technologies promise capacity gains. Journal of Air Transport Management 42 (C), 203-212. doi: 10.1016/j.jairtraman.2014.10.005 
Kannegiesser, M., Günther, H.-O., Autenrieb, N., 2015. The time-to-sustainability optimization strategy for sustainable supply network design. Journal of Cleaner Production 108, 1-13. doi:10.1016/j.jclepro.2015.06.030

Kavakeb, S., Nguyen, T.T., McGinley, K., Yang, Z., Jenkinson, I., Murray, R., 2015. Green vehicle technology to enhance the performance of a European port: A simulation model with a cost-benefit approach. Transportation Research Part C: Emerging Technologies 60, 169-188. doi:10.1016/j.trc.2015.08.012

Krüger, J., Lien, T.K., Verl, A., 2009. Cooperation of human and machines in assembly lines. CIRP Annals - Manufacturing Technology 58, 628-646. doi:10.1016/j.cirp.2009.09.009

Kumar, A., Rahman, S., 2014. RFID-enabled process reengineering of closed-loop supply chains in the healthcare industry of Singapore. Journal of Cleaner Production 85, 382-394. doi:10.1016/j.jclepro.2014.04.037

Lee, B.K., Low, J.M.W., Kim, K.H., 2015. Comparative evaluation of resource cycle strategies on operating and environmental impact in container terminals. Transportation Research Part D: Transport and Environment 41, 118-135. doi:10.1016/j.trd.2015.09.014

Lee, R.J.V., Leonard R., 1990. Changing role of humans within an integrated automated guided vehicle system. Computer-Integrated Manufacturing Systems 3 (2), 115-120. doi: 10.1016/0951-5240(90)90114-T

Leite, L.F.V., Esposito, R.M.A.,Vieira, A.P., Lima, F., 2015. Simulation of a production line with automated guided vehicle: A case study. Independent Journal of Management \& Production 6 (2), 269-285. doi: 10.14807/ijmp.v6i2.257 
Leriche, D., Oudani, M., Cabani, A., Hoblos, G., Mouzna, J., Boukachour, J., El Hilali Alaoui, A., 2015. Simulating new logistics system of Le Havre Port. IFAC Proceedings 48 (3), 418-423. doi:10.1016/j.ifacol.2015.06.117

Liu, C.I., Jula, H., Vukadinovic, K. and Ioannou, P., 2004. Automated guided vehicle system for two container yard layouts. Transportation Research Part C: Emerging Technologies 12 (5), 349-368. doi: 10.1016/j.trc.2004.07.014

Lozano, R., 2012. Towards better embedding sustainability into companies’ systems: An analysis of voluntary corporate initiatives. Journal of Cleaner Production 25, 14-26. doi:10.1016/j.jclepro.2011.11.060

Luo, J., Wu, Y., 2015. Modelling of dual-cycle strategy for container storage and vehicle scheduling problems at automated container terminals. Transportation Research Part E: Logistics and Transport Review 79, 49-64. doi:10.1016/j.tre.2015.03.006

Lyon, T.P., Michelin, M., Jongejan, A., Leahy, T., 2012. Is “smart charging” policy for electric vehicles worthwhile?. Energy Policy 41, 259-268. doi: 10.1016/j.enpol.2011.10.045

Manzini, R., Bozer, Y., Heragu, S., 2015. Decision models for the design, optimization and management of warehousing and material handling systems. International Journal of Production Economics 170, 711-716. doi:10.1016/j.ijpe.2015.08.007

Martín -Soberón, A.M., Monfort, A., Sapiña, R., Monterde, N., Calduch, D., 2014. Automation in Port Container Terminals. Procedia - Social Behavioral Sciences 160, 195-204. doi:10.1016/j.sbspro.2014.12.131 
Material Handling Industry (MHI) Annual Industry Report 2016, Accelerating change: How innovation is driving digital, always-on supply chains. https://www.mhi.org/publications/report (accessed 09.04.2016)

Matsuda, M., Kashiwase, K., Sudo, Y., 2012. Agent oriented construction of a digital factory for validation of a production scenario. Procedia CIRP 3, 115-120. doi:10.1016/j.procir.2012.07.021

Matsuda, M., Kimura, F., 2013. Usage of a digital eco-factory for green production preparation. Procedia CIRP 7, 181-186. doi: 10.1016/j.procir.2013.05.031

Meyr, H., Wagner, M., Rohde, J., 2002. Structure of advanced planning systems. In: Stadtler, H., Kilger, C. (Eds.), Supply Chain Management and Advanced Planning—Concepts, Models Software and Case Studies, Berlin, pp. 99-104.

Milch, V., Laumann, K., 2016. Interorganizational complexity and organizational accident risk: A literature review. Safety Science 82, 9-17. doi:10.1016/j.ssci.2015.08.010

Negahban, A., Smith, J.S., 2014. Simulation for manufacturing system design and operation: Literature review and analysis. Journal of Manufacturing Systems 33, 241-261. doi:10.1016/j.jmsy.2013.12.007

Parreira, J., Meech, J., 2011. Autonomous haulage systems - Justification and opportunity. Lecture Notes in Computer Science (including Subser. Lect. Notes Artif. Intell. Lect. Notes Bioinformatics) 6752, 63-72. doi:10.1007/978-3-642-21538-4_7

Peterson, S.B., Michalek, J.J., 2013. Cost-effectiveness of plug-in hybrid electric vehicle battery capacity and charging infrastructure investment for reducing US gasoline consumption. Energy Policy 52, 429-438. doi: 10.1016/j.enpol.2012.09.059 
Reina, G., Milella, A., Rouveure, R., Nielsen, M., Worst, R., Blas, M.R., 2015. Ambient awareness for agricultural robotic vehicles. Biosystems Engineering, 1-19. doi:10.1016/j.biosystemseng.2015.12.010

Rich, P., 1992. The organizational taxonomy: definition and design. The Academy of Management Review 17 (4), 758-781. doi: 10.5465/AMR.1992.4279068

Roh, J., Hong, P., Min, H., 2014. Implementation of a responsive supply chain strategy in global complexity: The case of manufacturing firms. International Journal of Production Economics 147 (Part B), 198-210. doi: 10.1016/j.ijpe.2013.04.013

Sabattini L., Digani V., Secchi C., Cotena G., Ronzoni D., Foppoli M., Oleari F., 2013. Technological roadmap to boost the introduction of AGVs in industrial applications, Proceedings - 2013 IEEE 9th International Conference on Intelligent Computer Communication and Processing, ICCP 2013 6646109, 203-208. doi: 10.1109/ICCP.2013.6646109

Santa-Eulalia, L. A., D'Amours, S., Frayet, J.M., 2012. Agent-based simulations for advanced supply chain planning: The FAMASS methodological framework for requirements analysis. International Journal of Computer Integrated Manufacturing, 25 (10), 963-980. doi: 10.1080/0951192X.2011.652177

Schmidt, J., Eisel, M., Kolbe, L.M., 2014. Assessing the potential of different charging strategies for electric vehicle fleets in closed transport systems. Energy Policy 74, 179-189. doi:10.1016/j.enpol.2014.08.008

Schmidt, J., Meyer-Barlag, C., Eisel, M., Kolbe, L.M., Appelrath, H.-J., 2015. Using battery-electric AGVs in container terminals - Assessing the potential and optimizing the economic viability. Research in Transportation Business \& Management 17, 99-111. doi:10.1016/j.rtbm.2015.09.002 
Shapiro, J., 2000. Modeling the supply chain. Duxbury: Pacific Grove.

Shukla, A., Karki, H., 2016. Application of robotics in offshore oil and gas industry-A review Part II. Robotics and Autonomous Systems 75, 508-524. doi:10.1016/j.robot.2015.09.013

Tranfield, D., Denyer, D., Smart, P., 2003. Towards a methodology for developing evidence-informed management knowledge by means of systematic review. British Journal of Management 14, 207-222. doi: 10.1111/1467-8551.00375

Tsolakis, N.K., Keramydas, C.A., Toka, A.K., Aidonis, D.A., Iakovou, E.T., 2014. Agrifood supply chain management: A comprehensive hierarchical decisionmaking framework and a critical taxonomy. Biosystems Engineering 120, 47-64. doi: 10.1016/j.biosystemseng.2013.10.014

Ullrich, G., 2015. Automated guided vehicle systems, second ed., Springer-Verlag Berlin Heidelberg. doi: 10.1007/978-3-662-44814-4

Ventura, J.A., Pazhani, S., Mendoza, A., 2015. Finding optimal dwell points for automated guided vehicles in general guide-path layouts. International Journal of Production Economics 170 (Part C), 850-861. doi: 10.1016/j.ijpe.2015.03.007

Ventura, J.A., Rieksts, B.Q., 2009. Optimal location of dwell points in a single loop AGV system with time restrictions on vehicle availability. European Journal of Operational Research 192, 93-104. doi:10.1016/j.ejor.2007.09.014

Verdouw, C.N., Wolfert, J., Beulens, A.J.M., Rialland, A., 2016. Virtualization of food supply chains with the internet of things. Journal of Food Engineering 176, 128-136. doi: 10.1016/j.jfoodeng.2015.11.009 
Vis, F.A.I., 2006. Survey of research in the design and control of automated guided vehicle systems. European Journal of Operational Research 170, 3, 677-709. doi:10.1016/j.ejor.2004.09.020

Wang, S., Wan, J., Li, D., Zhang, C., 2016. Implementing Smart Factory of Industrie 4.0: An Outlook. International Journal of Distributed Sensor Networks 2016, 1-13. doi:10.1155/2016/3159805

Wu, H., Lv, K., Liang, L. and Hu, H., In Press. Measuring performance of sustainable manufacturing with recyclable wastes: A Case from China's iron and steel industry. Omega.

Xin, J., Negenborn, R.R., Corman, F., Lodewijks, G., 2015a. Control of interacting machines in automated container terminals using a sequential planning approach for collision avoidance. Transportation Research Part C: Emerging Technologies 60, 377-396. doi: 10.1016/j.trc.2015.09.002

Xin, J., Negenborn, R.R., Lodewijks, G., 2014. Energy-aware control for automated container terminals using integrated flow shop scheduling and optimal control. Transportation Research Part C: Emerging Technologies 44, 214230. doi:10.1016/j.trc.2014.03.014

Xin, J., Negenborn, R.R., Lodewijks, G., 2015b. Event-driven receding horizon control for energy-efficient container handling. Control Engineering Practice 39, 45-55. doi:10.1016/j.conengprac.2015.01.005 
Table 1. High level AGV literature categorization.

\begin{tabular}{|c|c|c|}
\hline Field of Application & System Design Issues & System Architecture \\
\hline Container terminal & Facility layout & Centralized \\
\hline Flexible manufacturing system & Transportation network & Hierarchical \\
\hline Warehouse management & Vehicle requirements & Decentralized \\
\hline Material handling & Control systems & \\
\hline Automotive manufacturing & Software management systems & \\
\hline High technology products & & \\
\hline Agriculture & & \\
\hline Mines & & \\
\hline Health management system & & \\
\hline
\end{tabular}


Table 2. Hierarchical decision-making framework.

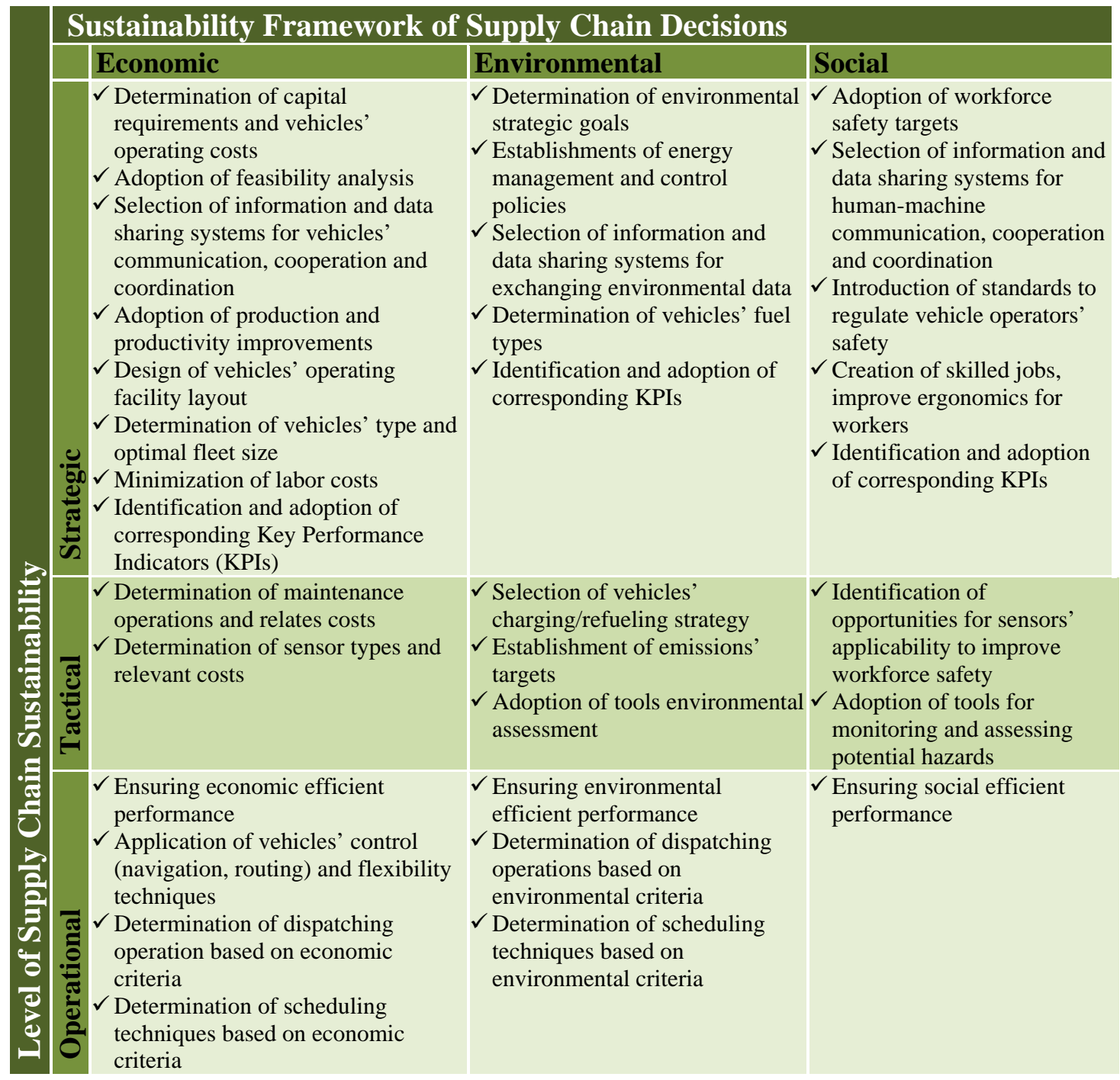


Table 3. Economic sustainability decision variables.

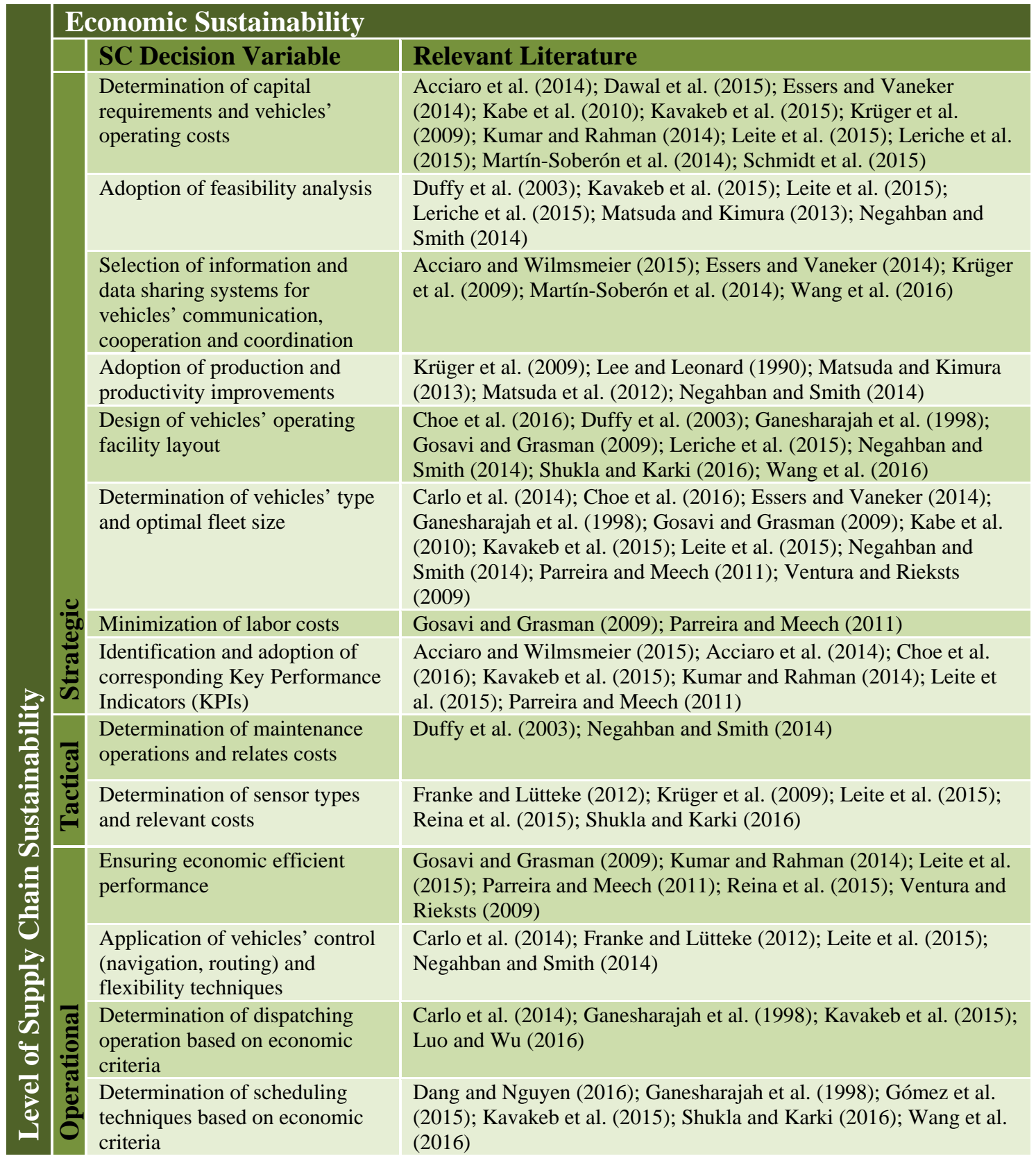


Table 4. Environmental sustainability decision variables.

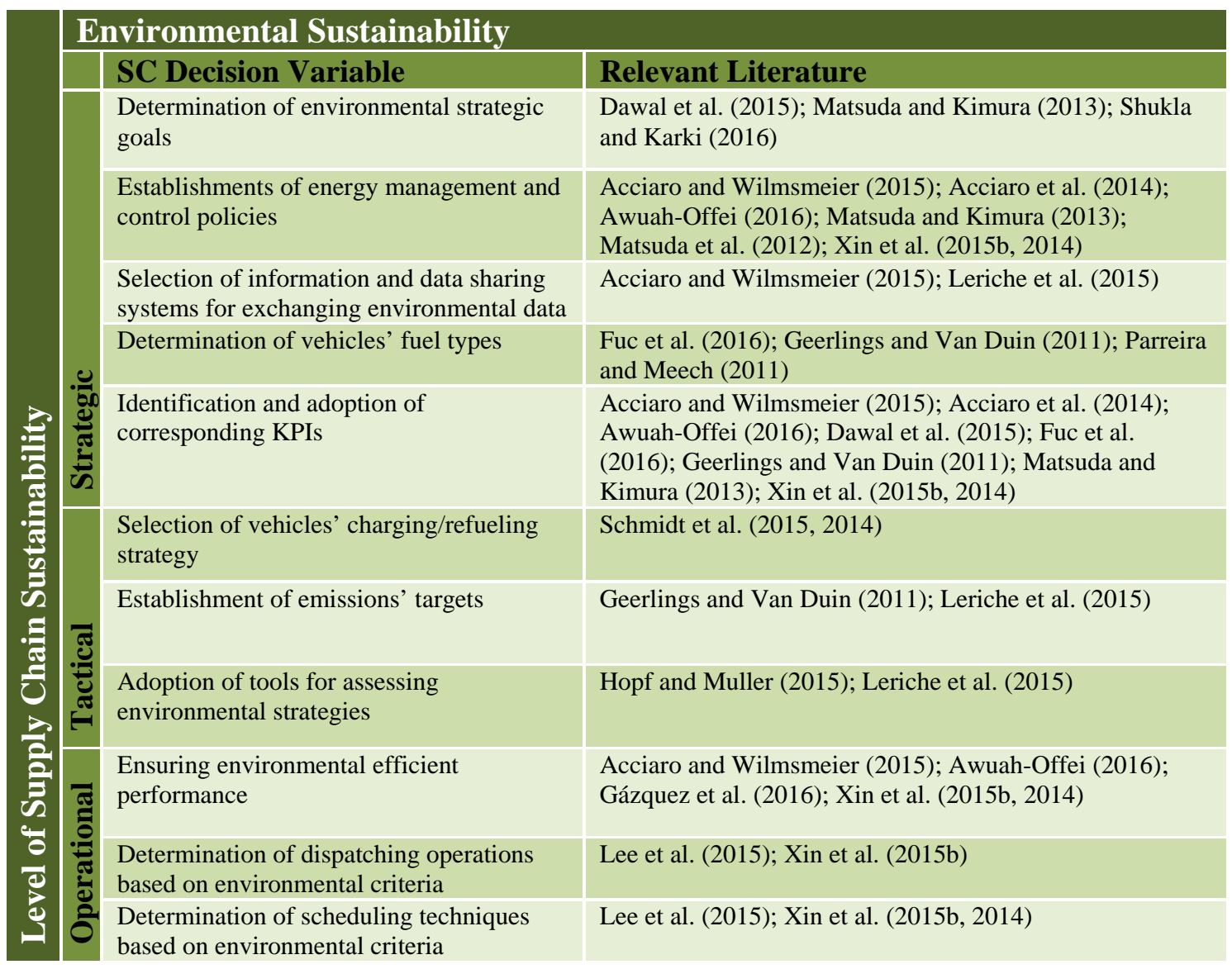


Table 5. Social sustainability decision variables.

\begin{tabular}{|c|c|c|c|}
\hline & \multicolumn{3}{|c|}{ Social Sustainability } \\
\hline & & SC Decision Variable & Relevant Literature \\
\hline \multirow{5}{*}{\multicolumn{2}{|c|}{ 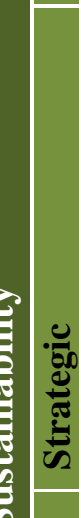 }} & $\begin{array}{l}\text { Adoption of workforce safety } \\
\text { targets }\end{array}$ & $\begin{array}{l}\text { Duffy et al. (2003); Ganesharajah et al. (1998); Leite et al. (2015); } \\
\text { Martín-Soberón et al. (2014); Shukla and Karki (2016) }\end{array}$ \\
\hline & & $\begin{array}{l}\text { Selection of information and data } \\
\text { sharing systems for human-machine } \\
\text { communication, cooperation and } \\
\text { coordination }\end{array}$ & $\begin{array}{l}\text { Essers and Vaneker (2014); Krüger et al. (2009); Lee and Leonard } \\
\text { (1990); Shukla and Karki (2016) }\end{array}$ \\
\hline$\underset{D}{D}$ & & $\begin{array}{l}\text { Introduction of standards and } \\
\text { regulations to improve } \\
\text { human/operators safety }\end{array}$ & Awuah-Offei (2016); Kabe et al. (2010); Krüger et al. (2009) \\
\hline & & $\begin{array}{l}\text { Creation of skilled jobs, improve } \\
\text { ergonomics for workers }\end{array}$ & Duffy et al. (2003); Krüger et al. (2009); Lee and Leonard (1990) \\
\hline . & & $\begin{array}{l}\text { Identification and adoption of } \\
\text { corresponding KPIs }\end{array}$ & Duffy et al. (2003); \\
\hline ह & 들 & $\begin{array}{l}\text { Identification of opportunities for } \\
\text { sensors' applicability to improve } \\
\text { workforce safety }\end{array}$ & $\begin{array}{l}\text { Gázquez et al. (2016); Reina et al. (2015); Shukla and Karki } \\
\text { (2016) }\end{array}$ \\
\hline 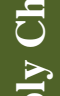 & E्ञ & $\begin{array}{l}\text { Adoption of tools for monitoring } \\
\text { and assessing potential hazards }\end{array}$ & Duffy et al. (2003); Gómez et al. (2015) \\
\hline 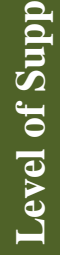 & 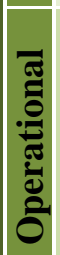 & $\begin{array}{l}\text { Ensuring social efficient } \\
\text { performance }\end{array}$ & $\begin{array}{l}\text { Awuah-Offei (2016); Duffy et al. (2003); Krüger et al. (2009); } \\
\text { Leite et al. (2015); Reina et al. (2015) }\end{array}$ \\
\hline
\end{tabular}

